\title{
Mistisisme Sastra Lisan: Kearifan Lingkungan dalam Tradisi Cepetan
}

\section{Alas}

\author{
Onok Yayang Pamungkas ${ }^{\mathrm{a}}$, Aan Andyanto ${ }^{\mathrm{b}}$ \\ ${ }^{\mathrm{a}, \mathrm{b}}$ Program Studi Pendidikan Bahasa Indonesia, Universitas Ma'arif Nadhlatul Ulama Kebumen \\ onokyayangpamungkas@gmail.com ${ }^{\text {a }}$, $\underline{\text { anandyanto01@ @mail.com }}^{\text {b }}$
}

\begin{abstract}
Abstrak
Penelitian ini mengkaji tradisi kebudayaan sebagai aktivitas dan proses berpikir, bertindak dan bersikap secara arif dan bijaksana dalam mengamati, memanfaatkan dan mengolah alam sebagai suatu timbal balik antara manusia dengan lingkungan. Tujuan penelitian ini mendeskripsikan aspek, bentuk harmonisasi masyarakat, dan nilai-nilai pendidikan dalam tradisi Cepetan Alas bagi warga Desa Karanggayam. Penelitian ini menggunakan model penelitian deskriptif kualitatif. Data utama yang digunakan meliputi hasil wawancara dengan narasumber tentang kesenian tradisi Cepetan Alas. Teknik analisis data menggunakan teknik analisis semiotik. Hasil penelitian menunjukkan bahwa, kesenian tradisi Cepetan Alas merupakan budaya turun-temurun dari leluhur terdahulu sehingga kemudian diwariskan kepada generasi penerus di Desa Karanggayam sebagai bagian dari tradisi. Kesenian ini sebagai wujud harmonisasi antara manusia, alam dan Tuhan tentang kearifan lingkungan yang berkembang baik di masyarakat lokal maupun nasional. Aspek sosial budaya dalam tradisi Cepetan Alas diantaranya masyarakat masih memercayai adanya makhluk gaib yang menghuni alas Curug Bandung dan tetap menjaga ritual adat dalam setiap pembukaan tradisi Cepetan Alas. Paguyuban Cinta Karya Budaya sebagai wadah bagi masyarakat Desa Karanggayam untuk tetap menjaga dan melestarikan keberadaan tradisi Cepetan Alas agar tidak tergempur oleh perkembangan budaya asing. Tradisi Cepetan Alas memiliki nilainilai pendidikan yang dapat menjadi teladan bagi generasi penerus yang melekat dalam kehidupan masyarakat. Simpulan penelitian ini adalah, tradisi Cepetan Alas merupakan bentuk kebudayaan masyarakat yang hingga saat ini masih terjaga dan dilestarikan dalam sebuah paguyuban kesenian. Paguyuban Cinta Karya Budaya sebagai wadah masyarakat melanjutkan estafet regenerasi tradisi Cepetan Alas di Desa Karanggayam dengan tetap menjaga kearifan lingkungan yang melekat dalam kesenian tersebut.
\end{abstract}

Kata Kunci: Folklor, Cepetan Alas, aspek sosial budaya, paguyuban cinta karya budaya, nilai pendidikan

\begin{abstract}
This study examines cultural traditions as activities and processes of thinking, acting and acting wisely and wisely in observing, utilizing and processing nature as a reciprocity between humans and the environment. The purpose of this study is to describe aspects, forms of community harmonization, and educational values in the Cepetan Alas tradition for residents of Karanggayam Village. This study uses a qualitative descriptive research model. The main data used include the results of
\end{abstract}


interviews with informants about the traditional arts of Cepetan Alas. The data analysis technique used semiotic analysis technique. The results showed that the traditional art of Cepetan Alas was a hereditary culture from previous ancestors so that it was then passed on to the next generation in Karanggayam Village as part of the tradition. This art is a form of harmonization between humans, nature and God regarding environmental wisdom that develops both in local and national communities. Socio-cultural aspects in the Cepetan Alas tradition include the community still believing in the existence of supernatural beings that inhabit the Curug Bandung base and maintaining traditional rituals in every opening of the Cepetan Alas tradition. Paguyuban Cinta Karya Budaya as a forum for the people of Karanggayam Village to maintain and preserve the existence of the Cepetan Alas tradition so as not to be attacked by foreign cultural developments. The Cepetan Alas tradition has educational values that can serve as role models for future generations inherent in people's lives. The conclusion of this research is, the Cepetan Alas tradition is a form of community culture that is still maintained and preserved in an art community. Paguyuban Cinta Karya Budaya as a forum for the community to continue the regeneration relay of the Cepetan Alas tradition in Karanggayam Village while maintaining the environmental wisdom inherent in the art.

Keywords: Folklore, Cepetan Alas, socio-cultural aspects, cinta karya budaya community, educational value

\section{Pendahuluan}

Indonesia merupakan negara dengan budaya dan tradisi yang beraneka ragam serta sudah ada secara turun-temurun oleh nenek moyang antara lain kesenian-kesenian, makanan, dan pola hidup masyarakat. Salah satu diantara tradisi tersebut adalah tradisi lisan (orality), yaitu tradisi yang lebih banyak menggunakan lisan, berupa mulut dan juga indra pendengaran (Agustin, Mutia \& Susanti, 2020: 139-144). Tradisi lisan telah menjadi salah satu budaya lokal di Indonesia dan kehadirannya tak lekang oleh waktu dan masih dipelihara keberadaanya. Pemeliharaan kebudayaan ini sesuai dengan pernyataan Cooper, dkk. (2016: 1-12) yang menjadi fokusnya adalah pada budaya pedesaan tradisional - baik di negara berkembang atau kelompok adat, seperti Bangsa Kanada, di negara maju - dan manfaat utama dipahami sebagai pemeliharaan budaya mereka.

Cerita rakyat atau folklor yang ada di dalam masyarakat merupakan suatu bentuk cerita dari mulut ke mulut yang sampai sekarang masih dipercaya oleh masyarakat setempat. Folklor merupakan bagian dari kebudayaan berupa karya sastra yang lahir dan berkembang dalam masyarakat tradisional. Danandjaja (1994: 2) menyatakan folklor secara keseluruhan adalah: sebagian kebudayaan suatu kolektif, yang tersebar dan diwariskan turun-temurun, di antara kolektif macam apa saja, secara tradisional dalam versi yang berbeda, baik dalam bentuk lisan maupun contoh yang disertai dengan gerak isyarat alat-alat pembantu mengingat. Umumnya cerita rakyat mempunyai makna dan amanat yang tersembunyi dibalik cerita yang tersebar di masyarakat. Hal ini sesuai dengan pernyataan Lizawati (2018: 19-26) bahwa cerita rakyat yang didengar secara tidak langsung akan membentuk sikap dan moral seseorang. Cerita rakyat juga bertujuan untuk menghormati, memuja mohon keselamatan dan ucapan rasa syukur kepada Tuhan melalui para leluhur dan peninggalannya. Mereka percaya bahwa keterbatasan yang 
dimiliki oleh manusia dapat diatasi dengan keterlibatan para leluhur dan peninggalannya, sehingga mempercayai dan meyakini cerita rakyat tersebut.

Pada dasarnya cerita rakyat senantiasa mengalami perubahan dari masa ke masa, bahkan dari penuturan satu ke penuturan lain dalam waktu yang berbeda, meski dari kelompok atau individu yang sama. Kepekaan dan daya kritis di lingkungan sekitar lebih diutamakan sebagai jembatan menuju generasi literat, yaitu generasi yang memiliki ketrampilan berpikir kritis terhadap segala informasi untuk mencegah reaksi yang bersifat emosional. Budaya inilah yang nampaknya belum dimiliki sebagian besar masyarakat Indonesia.

Dalam kurun waktu tertentu, masyarakat mengalami pergeseran kebudayaan yang dipengaruhi oleh proses belajar dari kebudayaan lain, perubahan geografis dan proses pembaharuan (inovasi). Pergeseran kebudayaan ini bisa menyebabkan munculnya kebudayaan baru dan hilangnya kebudayaan lama. Hanya kebudayaan yang dominan yang akhirnya bisa bertahan. Hal ini sudah sangat jelas dirasakan diera globalisasi seperti saat ini. Cerita rakyat maupun folklor merupakan salah satu upaya manusia untuk melestarikan kebudayaan dan tradisi yang telah dibuat oleh leluhurnya dan diteruskan secara turun temurun kepada masyarakat. Diharapkan dengan cerita rakyat atau folklor tersebut manusia dapat mengetahui asal-usul kejadian dimana cerita rakyat itu diceritakan kepada masyarakat.

Salah satu tradisi lisan yang ada di Indonesia yaitu berkembang di daerah Kebumen. Kebumen merupakan salah satu kabupaten di Provinsi Jawa Tengah di bagian selatan pulau Jawa. Terdapat banyak kebudayaan di wilayah Kebumen berupa cerita rakyat yang tersebar di pelosok-pelosok pedesaan, salah satunya tradisi Cepetan Alas. Tradisi Cepetan Alas merupakan kesenian tradisi yang masih relevan dan masih dilestarikan oleh masyarakat pemiliknya di Desa Karanggayam Kecamatan Karanggayam Kabupaten Kebumen. Tradisi Cepetan Alas adalah objek yang akan dilaksanakan dalam penelitian.

Tradisi Cepetan Alas yang berkembang hingga saat ini, merupakan kesenian yang bukan hanya hiburan semata, melainkan adanya nilai dan pesan yang disampaikan dalam pagelaran tradisi Cepetan Alas di Desa Karanggayam tersebut. Penggunaan topeng dan sesajen sebagai simbol juga memiliki makna dari setiap karakter dan kegiatan yang dilakukan selama pagelaran. Penelitian ini bertujuan mengkaji aspek sosial budaya yang terkandung dalam tradisi Cepetan Alas, mendeskripsikan upaya masyarakat dalam melestarikan kebudayaan, dan menelaah nilai-nilai yang disampaikan dalam pagelaran tradisi Cepetan Alas.

\section{Metodologi Penelitian}

Penelitian ini merupakan bentuk penelitian kualitatif dengan studi kasus yang masih jarang ditemukan. Metode yang digunakan dalam penelitian yaitu metode deskriptif kualitatif. Kualitas penafsiran dalam metode kualitatif dibatasi oleh hakikat fakta-fakta sosial, artinya fakta sosial adalah fakta-fakta sebagaimana ditafsirkan oleh subjek (Ratna, 2004: 47). Sumber data dalam penelitian ini adalah hasil wawancara dengan narasumber secara langsung, asal usul sejarah tradisi Cepetan Alas khas Desa Karanggayam. Data penelitian ini berupa kata, frasa dan kalimat yang secara definitif maupun sugestif mengandung aspek kebudayaan dan nilai-nilai pendidikan karakter dalam tradisi Cepetan Alas di Desa Karaggayam.

Teknik pengumpulan data dilakukan dengan cara observasi, dokumentasi dan wawancara beberapa tokoh masyarakat di Desa Karanggayam yang berkaitan, baik secara 
Universitas Ma'arif Nahdlatul Ulama Kebumen langsung maupun tidak langsung dengan tradisi Cepetan Alas. Hasil penelitian dianalisis dengan menggunakan teknik analisis semiotik dan diuji keabsahannya dengan menggunakan triangulasi. Triangulasi yang dilakukan adalah triangulasi sumber, metode dan teori (Warsito, 2011). Semiotik adalah ilmu tentang tanda-tand, ilmu ini menganggap bahwa fenomena sosial atau masyarakat dan kebudayaan itu merupakan tanda-tanda. Semiotik mempelajari sistem-sistem, aturan, dan konveksi, yang memungkinkan tanda-tanda tersebut mempunyai arti (Pradopo dalam Zikri, 2018). Analisis ini diperlukan untuk mencari informasi lebih dalam terkait simbol dan tanda yang ada dalam tradisi Cepetan Alas.

\section{Hasil Dan Pembahasan}

Berdasarkan analisis data yang telah dilakukan, terdapat beberapa hasil penelitian: (a) aspek sosial budaya tradisi Cepetan Alas; (b) upaya masyarakat dalam melestarikan tradisi Cepetan Alas; dan (c) nilai pendidikan yang terkandung dalam tradisi Cepetan Alas di Desa Karanggayam. Tradisi Cepetan Alas merupakan salah satu bentuk kebudayaan yang diwariskan secara turun-temurun di Desa Karanggayam. Menurut Koentjaraningrat (2000:1), banyak orang mengartikan konsep kebudayaan itu dalam arti yang terbatas, ialah pikiran, karya, dan hasil karya manusia yang memenuhi hasratnya akan keindahan. Sebaliknya, banyak orang terutama para ahli ilmu sosial, mengartikan konsep kebudayaan itu dalam arti yang amat luas yaitu seluruh total dari pikiran, karya, dan hasil karya manusia yang tidak berakar kepada nalurinya, dan yang karena itu hanya bisa dicetuskan oleh manusia sesudah proses belajar.

\subsection{Aspek Sosial Budaya Tradisi Cepetan Alas dalam Perspektif Fungsi dan Semiotik}

Aspek adalah sudut pandangan (Untara, 2014: 34). Sosial adalah segala sesuatu yang berkenaan dengan masyarakat (Untara, 2014: 497). Aspek sosial dapat diartikan sebagai penginterpretasian terhadap sudut pandang masyarakat. Aspek sosial merupakan sesuatu yang memperhitungkan nilai penting antara sastra dan masyarakat, sehingga untuk memahami permasalahan dalam suatu karya sastra, akan berhubungan dengan realita sosial yang terdapat dalam masyarakat (Sukmana, 2017). Aspek sosial suatu karya sastra menangkap kenyataan kehidupan melalui berbagai permasalahannya.

Budaya adalah "daya dari budi" yang berupa cipta, karsa, dan rasa, sedangkan "kebudayaan" adalah hasil dari cipta, karsa, dan rasa itu (Koentjaraningrat dalam Sujarwa, 1998: 7). Budaya adalah sebuah sistem yang mempunyai koherensi. Bentuk-bentuk simbolis yang berupa kata, benda, laku, mite, sastra, lukisan, nyanyian, musik, kepercayaan mempunyai kaitan erat dengan konsep-konsep epistemologis dari sistem pengetahuan masyarakatnya (Kuntowijaya, 1999). Berikut tersaji pada Tabel 1. bentuk aspek kebudayaan yang terdapat dalam tradisi Cepetan Alas.

Tabel 1 Bentuk Aspek Kebudayaan Tradisi Cepetan Alas

\begin{tabular}{|c|c|c|}
\hline No. & Aspek Kebudayaan & Bentuk Kegiatan \\
\hline \multirow[t]{2}{*}{1} & Aspek Sosial & - $\quad$ Hidup berdampingan dengan alam \\
\hline & & $\begin{array}{l}\text { Manusia percaya dengan adanya makhluk penghuni } \\
\text { alas Curug Bandung, menunjukkan bahwa yang hidup } \\
\text { di alam bukan hanya manusia saja, ada makhluk gaib }\end{array}$ \\
\hline
\end{tabular}


Universitas Ma'arif Nahdlatul Ulama Kebumen No. Aspek Kebudayaan Bentuk Kegiatan

yang menyatu dengan alam

2 Aspek Budaya

a. Ritual Adat

- Memasang sesajen

Setiap malam Jumat Kliwon dilakukan ritual memberikan sesajen dengan membakar kemenyan dan meletakkan bunga di sekitar tempat menyimpan topeng dengan doa-doa yang diwariskan turun-temurun

b. Kepercayaan

- Percaya adanya makhluk gaib

Masyarakat

Masyarakat percaya bahwa di alas Curug Bandung terdapat makhluk gaib yang menghuni dan tinggal di alas tersebut. Dengan memasang sesajen, diharapkan makhluk gaib tersebut tidak mengganggu manusia dan dapat hidup bersama-sama

Berdasarkan hasil penelitian tersebut, dilakukan analisis aspek sosial budaya tradisi Cepetan Alas dalam perspektif fungsi dan semiotik. Menurut Bascom dalam Danandjaja (1994: 19) fungsi cerita rakyat adalah sebagai berikut: 1) sebagai sistem proyeksi yakni sebagai alat pencermin angan-angan suatu kolektif; 2) sebagai alat-alat pengesahan pranata-pranata lembaga-lembaga kebudayaan; 3) sebagai alat pendidikan anak; dan 4) sebagai alat pemaksa dan pengawas agar norma-norma masyarakat akan selalu dipatuhi anggota kolektifnya. Berdasarkan uraian tersebut, fungsi cerita rakyat dalam kesenian tari Cepetan Alas tersaji dalam Tebel 2.

Tabel 2 Fungsi tradisi Cepetan Alas dalam Folklor

\begin{tabular}{|c|c|c|}
\hline No. & Fungsi Folklor & Proyeksi Kegiatan \\
\hline 1 & Sistem Proyeksi & $\begin{array}{l}\text { Alas Curug Bandung sebagai tujuan tempat persembahan } \\
\text { memohon izin kepada Tuhan Yang Maha Kuasa dengan } \\
\text { membawa sesajen sebagai bentuk rasa syukur dan supaya } \\
\text { penghuni alas tidak marah ketika lahan dibabad dan } \\
\text { dimanfaatkan oleh masyarakat }\end{array}$ \\
\hline 2 & $\begin{array}{l}\text { Alat Pengesahan Pranata } \\
\text { Kelembagaan } \\
\text { Kebudayaan }\end{array}$ & $\begin{array}{l}\text { Tradisi Cepatan Alas sudah di dibuatkan SK. Penetapan } \\
\text { oleh dinas terkait sebagai salah satu bentuk warisan leluhur } \\
\text { yang wajib dilestarikan dan dijaga keberadaannya }\end{array}$ \\
\hline 3 & Alat Pendidikan Anak & $\begin{array}{l}\text { Tradisi Cepetan Alas dijadikan kegiatan ekstrakurikuler di } \\
\text { sekolah sekolah sekitar Kecamatan Karanggayam dan } \\
\text { sekitarnya, sebagai wujud untuk menanamkan nilai moral } \\
\text { kepada generasi penerus kebudayaan }\end{array}$ \\
\hline 4 & $\begin{array}{l}\text { Alat Pemaksa dan } \\
\text { Pengawas }\end{array}$ & $\begin{array}{l}\text { Upacara ritual setiap malam Jumat Kliwon yang secara rutin } \\
\text { dilaksanakan dan prosesi kegiatan tradisi Cepetan Alas } \\
\text { selalu diawali dengan babad alas. }\end{array}$ \\
\hline
\end{tabular}


Universitas Ma'arif Nahdlatul Ulama Kebumen

Pada masa kini, telah dilahirkan berbagai karya seni yang tidak saja memiliki nilai estetika tinggi, tetapi juga memiliki simbol-simbol religi yang tinggi. Menurut Turner dalam Endraswara (2003: 172), simbol adalah unit atau bagian terkecil dalam ritual yang mengandung makna dari tingkah laku ritual khusus. Simbol dan makna merupakan dua unsur yang berbeda. Namun saling berkaitan bahkan saling melengkapi. Bentuk ragam topeng dalam tradisi Cepetan Alas secara simbolis memiliki arti dan maksud tertentu. Wujud sebuah topeng mempengaruhi sifat-sifat karakter yang dimunculkan berbeda. Ini berarti bahwa topeng menyimpan nilai-nilai moral secara simbolis. Topeng-topeng yang dikenakan oleh masing-masing pemain menggambarkan karakter. Sebuah topeng berkarakter baik (menggambarkan seorang putri dan ksatria) yang dijadikan sebagai pemimpin para .petani. Topeng lainnya menggambarkan simbol binatang (monyet, gajah) dan makhluk halus (cepet, banaspati, raksasa/buto dan lain-lain).

\subsection{Tradisi Cepetan Alas: Upaya Pelestarian Mistis menuju Harmonisasi Lingkungan}

Kesenian di suatu daerah memiliki sifat yang khas dibandingkan dengan unsur-unsur kebudayaan lainnya. Sifat yang dimaksud adalah bahwa kesenian dapat dinikmati oleh setiap orang tanpa mengenal batas kesukuan, kebangsaan, meskipun kesenian daerah berpedoman kepada sistem pengetahuan, kepercayaan, nilai, norma-norma yang hidup dalam masyarakat pemilik kesenian tersebut. Adanya kemajuan teknologi dan kehadiran kesenian lain tidak menutup kemungkinan terjadi dua hal. Pertama, kesenian tersebut akan hilang dengan sendirinya karena kurang dapat bersaing dengan kesenian lain yang ada. Kedua, justru sebaliknya kesenian tersebut berkembang dengan fungsi yang bergeser atau berubah, yaitu dari sarana upacara adat ritual menjadi hiburan semata. Oleh karena itu, masyarakat memegang peran penting dalam menentukan keberlangsungan budaya yang ada sehingga dapat tetap hidup dan berkembang.

Keberadaan Paguyuban Cinta Karya Budaya di Desa Karanggayam memang erat kaitannya dengan kemunculan tradisi Cepetan Alas yang juga berasal dari Desa Karanggayam. Dalam perkembangannya dari tahun ke tahun aktivitas Paguyuban Cinta Karya Budaya dinilai oleh masyarakat sekitar semakin jelas dan berdampak positif bagi upaya pembinaan kesenian di Karanggayam. Demikian pula perhatian pemerintah daerah juga semakin besar. Sebagai wujud perhatian tersebut, telah dilakukannya pembinaan organisasi terhadap Paguyuban Cinta Karya Budaya sebagai pelestari tradisi Cepetan Alas.

Kegiatan Paguyuban Cinta Karya Budaya terutama dalam festival kesenian baik yang diadakan oleh pemerintah daerah maupun yang diadakan di luar wilayah Kebumen merupakan bentuk usaha pemerintah daerah untuk merevitalisasi kesenian daerah Kebumen, khususnya tradisi Cepetan Alas. Melalui Paguyuban Cinta Karya Budaya tradisi Cepetan Alas mampu menunjukkan keberadaannya kepada masyarakat luas. Beberapa kegiatan festival yang telah diikuti merupakan bentuk sumbangsih paguyuban terhadap kehidupan kesenian tradisional.

Berdasarkan gambaran hasil penelitian, kesenian yang dilakukan oleh Paguyuban Cinta Karya Budaya dapat dikemukakan bahwa sangat mempengaruhi terhadap perkembangan tradisi Cepetan Alas baik dalam lingkup masyarakat Kebumen, maupun di luar wilayah Kebumen. Keberadaan tradisi Cepetan Alas di Kabupaten Kebumen pada saat ini masih tetap dilestarikan dengan baik dan kondisi yang demikian didukung pula oleh berbagai pihak yaitu masyarakat setempat, pelaku seni, pemerhati seni dan pemerintah daerah yang masih memperhatikan keberadaan tradisi Cepetan Alas sebagai aset budaya serta aset masyarakat Kabupaten Kebumen. 


\subsection{Tradisi Cepetan Alas: Warisan Nilai Pendidikan dari Leluhur Jawa}

Universitas Ma'arif Nahdlatul Ulama Kebumen

Berdasarkan hasil analisis, terdapat beberapa nilai pendidikan yang ada dalam tradisi Cepetan Alas, nilai-nilai tersebut adalah: (1) nilai budaya; (2) nilai religius; dan (3) nilai moral. Berikut penjelasan mengenai nilai-nilai yang terdapat dalam tradisi Cepetan Alas berdasarkan hasil wawancara dengan beberapa narasumber dalam Tabel 3.

\begin{tabular}{|c|c|c|}
\hline No. & Nilai Pendidikan & Bentuk Kegiatan \\
\hline \multirow[t]{2}{*}{1} & Nilai Budaya & Budaya gotong royong \\
\hline & & $\begin{array}{l}\text { Seorang tokoh masyarakat mengajak waragnya untuk } \\
\text { bersama-sama melakukan babad alas sebagai upaya } \\
\text { bertahan hidup pada masa paceklik dan pageblug yang } \\
\text { melanda Desa Karanggayam }\end{array}$ \\
\hline \multirow[t]{2}{*}{2} & Nilai Religius & Wangsit atau firasat \\
\hline & & $\begin{array}{l}\text { Mbah Lamijan (Almarhum) mendapatkan wangsit untuk } \\
\text { membuat karakter topeng dalam satu malam saja }\end{array}$ \\
\hline \multirow[t]{4}{*}{3} & Nilai Moral & - Usaha dan kerja keras \\
\hline & & $\begin{array}{l}\text { Masyarakat dengan penuh kesabaran, kerja keras dan } \\
\text { usaha yang maksimal sehingga mendapatkan hasil } \\
\text { pertanian yang subur dan panen yang melimpah dari } \\
\text { kegiatan babad alas di alas Curug Bandung }\end{array}$ \\
\hline & & - Perjuangan \\
\hline & & $\begin{array}{l}\text { Masyarakat gagah berani melawan ketakutannya sendiri } \\
\text { sehingga menjadi teladan bagi masyarakat untuk tidak } \\
\text { takut dengan hal-hal gaib, sebagai manusia kita } \\
\text { memberikan pengertian bahwa dalam dunia ini kita tidak } \\
\text { hidup sendirian, ada makhluk lain yang juga hidup } \\
\text { berdampingan dengan kita }\end{array}$ \\
\hline
\end{tabular}

Nilai-nilai yang disampaikan ini adalah tuturan baik yang disampaikan leluhur kepada keturunannya, memang terkadang dimasa sekarang ini di era modernisasi terkesan asing bagi orang-orang faktanya ada pesan baik yang memang dapat menjadi tuntunan hidup yang baik apabila dapat dilihat dari sudut pandang pendidikan. Tradisi Cepetan Alas ini bukan berarti hanya sekadar kesenian kuno peninggalan orang-orang jaman dulu tetapi terdapat pesan dan nilai baik bagi manusia. Tradisi Cepetan Alas sekilas hanya kesenian hiburan saja tetapi ada nilai lebihnya mengajarkan manusia untuk berbagi dengan makhluk Tuhan dan alam semesta. Orang Jawa mengenal alam semesta tidak hanya dengan ruang lingkup kecil tetapi sangatlah luas. Perlu digarisbawahi alam semesta ini bukan hanya yang terlihat secara kasat mata tetapi yang tidak bisa dilihat secara kasat matapun oleh orang Jawa dikenal dengan alam semesta seperti halnya jin-jin ataupun makhluk gaib masuk didalamnya.

Tradisi Cepetan Alas ini mengajarkan dimana manusia harus memiliki hubungan erat manuisa dengan manusia, manusia dengan alam, manusia dengan Tuhan. Hubungan erat antara manusia dengan manusia dalam tradisi Cepetan Alas ini terlihat dimana adanya kerjasama antar 
manusia untuk membuka lahan di alas Curug Bandung, hal ini terlihat jelas pembukaan lahan yang luas tidaklah mampu apabila dikerjakan oleh satu orang saja, tetapi terdapat kerjasama antar manusia. Nilai positifnya adalah gotong royong antar manusia sangatlah penting untuk meringankan beban yang ada. Hasil penelitian ini sesuai dengan penelitian Pratami, dkk. (2017: 76), masyarakat bersama-sama membuka hutan untuk pemukian dan pertanian baru.

Berdasarkan hasil penelitian, nilai pendidikan yang terkandung dalam tradisi Cepetan Alas diantaranya nilai budaya, nilai religius, dan nilai moral. Hasil penelitian ini sejalan dengan Himawan (2020: 35), ada tiga nilai dalam pendidikan karakter yaitu nilai budaya, nilai religius, dan nilai moral Persamaan penelitian ini dengan penelitian yang sudah penulis lakukan terletak pada cerita rakyat yang dikaji, penelitian yang dilakukan Himawan meneliti tentang "Ki Ageng Mangir" dengan judul Nilai Pendidikan Karakter dalam Cerita Rakyat Kabupaten Bantul "Ki Ageng Mangir" (Kajian Folklor).

\section{Kesimpulan}

Tradisi Cepetan Alas diwariskan secara turun-temurun dari generasi ke generasi sehingga keberadaannya tetap lestari hingga saat ini. Walaupun tergempur oleh perkembangan jaman dan teknologi yang semakin pesat, tradisi Cepetan Alas masih ada di Desa Karanggayam. Adanya generasi muda yang turut serta ikut dalam tradisi Cepetan Alas menjadikan generasi penerusnya selalu ada dan bertahan. Tradisi Cepetan Alas terus dijaga dalam sebuah wadah yang berbentuk paguyuban, yaitu Paguyuban Cinta Karya Budaya. Peran pemerintah yang ikut melestarikan kebudayaan lokal juga memberikan pengaruh yang luar biasa. Tradisi Cepetan Alas mengadung nilai-nilai baik bagi kehidupan masyarakat. Secara umum nilai tersebut diantaranya, nilai budaya, nilai religius dan nilai moral. Pesan-pesan atau nilai-nilai yang disampaikan terlihat jelas didalam pagelaran tradisi Cepetan Alas.

Tradisi Cepetan Alas dalam kajian fungsi folklor dan semiotik memberikan contoh berupa tanda dan simbol dalam peragaan kesenian tari. Simbol yang ada didalam tradisi Cepetan Alas tersebut mengandung makna yang berarti dalam kehidupan manusia. Seperti halnya sesajen, merupakan wujud rasa syukur kepada Tuhan Yang Maha Kuasa yang telah memberikan izin kepada masyarakat agar dapat memanfaatkan alas Curug Bandung untuk memenuhi kebutuhan masyarakat selama masa pageblug hingga saat in.

\section{Daftar Pustaka}

Agustin, D., Mutia, F. \& Susanti, W. D. 2020. Tradisi Lisan sebagai Salah Satu Sumber Eksplorasi Desain Arsitektur Nusantara (Studi Kasus Museum Purna Bhakti Pertiwi, Tugu Monas dan Gedung DPR/MPR RI). Jurnal Arsitektur. 17 (2), 139-144.

Cooper, N., Brady, E., Steen, H. \& Bryce, R. 2016. Aesthetic and Spiritual Values of Ecosystems: Recognising the Ontological and Axiological Plurality of Cultural Ecosystem 'Services'. Ecosystem Services. 20 (40): 1-12.

Danandjaja, J. 1994. Folklor Indonesia Ilmu Gosip, Dongeng, dan Lain-lain. Jakarta: Pustaka Utama Grafiti.

Endraswara, S. 2003. Metode Penelitian Kebudayaan. Yogyakarta: Gadjah Mada University Press. 
Himawan, R. 2020. Nilai Pendidikan Karakter dalam Cerita Rakyat Kabupaten Bantul "Ki Ageng Mangir" (Kajian Folklor). Jurnal Mimesis. 1(2): 77-85.

Koentjaraningrat. 2000. Kebudayaan Mentalitas Dan Pembangunan. Jakarta: PT. Gramedia Pustaka Utama.

Lizawati. 2018. Cerita Rakyat sebagai Sarana Pendidikan Karakter dalam Membangun Generasi Literat. Jurnal Pendidikan Bahasa dan Sastra Indonesia. 1 (1): 19-26.

Pratami, A. Z., Septiningrum E. S., Istinganatuzzakiyah, Hidayah, R. 2017. Pendidikan Karakter Dalam Kesenian Cepetan Alas pada Siswa Sekolah Dasar di Kebumen. Inovasi Pendidikan. 21 (1): 72-78.

Ratna, N. K. 2004. Teori, Metode, dan Teknik Penelitian Sastra (Strukturalisme Hingga Postrukturalisme, Perspektif Wacana Naratif). Yogyakarta: Pustaka Pelajar.

Sukmana, E. 2017. Aspek Sosial Budaya dalam Cerita Rakyat Enyeng di Desa Cipancar. Jurnal Pendidikan dan Sastra Indonesia. 1 (6): 18-23.

Sujarwa, P. 1998. Manusia dan Fenomena Budaya Menuju Perspektif Moralitas Agama. Yogyakarta: Universitas Ahmad Dahlan Yogyakarta.

Untara, W. 2014. Kamus Bahasa Indonesia. Yogyakarta: Indonesia Tera.

Warsito. 2011. Kajian Struktural, Nilai Kearifan Lokal dan Nilai Pendidikan Folklore Di Kabupaten Magetan. Tesis. Surakarta: Universitas Sebelas Maret.

Zikri, A. 2018. Cerita Asal-Usul Nama Tempat di Kecamatan Lembah Gumanti Kabupaten Solok. Skripsi. Padang: Universitas Andalas. 